\title{
Comunicação, subjetividade e transporte nas cidades
}

\section{Janice Caiafa}

Doutora em Antropologia pela Cornell University, Professora titular da Escola de Comunicação da Universidade Federal do Rio de Janeiro (UFRJ), poeta e pesquisadora do CNPq.

E-mail: janicecaiafa@gmail.com
Resumo: Neste trabalho propomos considerar num mesmo campo problemático organização midiática e ocupação urbana. Argumentamos que os diversos regimes de velocidade ou energéticas comunicacionais que se constroem envolvendo arranjos tanto de fluxos semióticos, como na comunicação remota ou nas transmissões televisivas, quanto de fluxos materiais, como nos transportes - incidem sobre os espaços das cidades e contribuem para produzir formas de sociabilidade e de subjetivação. Examinando os fenômenos do advento do automóvel e da televisão em meados do século passado e da irrupção recente das mídias digitais, buscamos analisar estas questões a partir de casos concretos nos contextos americano e brasileiro.

Palavras-chave: Processos Comunicativos; Transporte; Subjetividade; Espaço Urbano.

\section{Communication, subjectivity and transportation in cities}

Abstract: In this work we propose to bring media organization and occupation of urban space together in a common problematic field. We argue that the various speed regimes or communicative energetics - which involve semiotic fluxes, as in remote communication or in television broadcast, as well as material fluxes, as in the means of transportation - affect urban space and participate in the production of forms of sociability and subjectivity. In investigating the emergence of the automobile and the television in the mid- $20^{\text {th }}$ century as well as the more recent advent of digital media, we seek to analyze these issues through specific cases in the United States and in Brazil.

Keywords: Communicative Processes; Transportation; Subjectivity; Urban Space. 


\section{Arranjos diversos de comunicação/transporte e a produção de subjetividade}

Considerar fenômenos comunicacionais em contiguidade com questões de transporte, sobretudo no que concerne à mobilidade urbana, pode não ser sem proveito para esses dois campos de estudo, em geral separados, e não menos para se compreender a vida social nas cidades. Trata-se, de fato, de ideia antiga no campo dos estudos em comunicação que ficou esquecida e que até hoje é pouco explorada.

Charles Horton Cooley (1909: 61-65), um dos primeiros sociólogos que, no século XIX e início do século XX, se interessaram pelo fenômeno comunicacional, definia comunicação como um duplo mecanismo: comunicação material ou física, que consiste nas redes de infraestrutura de transporte, e comunicação psicológica, referida a símbolos e seus aparatos de conservação e transmissão. A comunicação envolveria um espectro que inclui gestos, tons de voz, a imprensa, o telefone, as ferrovias, o telégrafo e "qualquer que seja a aquisição mais recente na conquista do espaço e do tempo" (Ibid., grifos nossos). Um "sistema de comunicação" é uma "ferramenta", diz ele, ou uma "invenção progressiva" que afeta a vida dos indivíduos e instituições com suas qualidades de "ampliação e animação" e, ainda, como escreve mais adiante, seu "vigor difusivo".

Embora marginal, esta vertente, por outro lado, continua a ser construída por trabalhos que, de variadas maneiras, concebem a comunicação nesse sentido mais amplo de mobilidade e conquista do tempo e do espaço - o que, para alguns, permite reunir o desenvolvimento dos transportes e a circulação de mensagens

${ }^{1}$ Cf., por exemplo, Carey (1989), Haye (1980), Lemos (2009), Mattelard (1996), Morley (2011), Packer e Oswald (2010) e Virilio (1993). nas diversas mídias ${ }^{1}$.

É assim que, para David Morley (2011), colocar o problema da comunicação envolveria distinguir "mobilidades diferenciais", estudando a regulação imposta tanto aos fluxos materiais quanto aos simbólicos. André Lemos (2009: 28) argumenta que a mobilidade compreende o movimento de pessoas, commodities e objetos assim como a dimensão informacional. Estes dois aspectos são indissociáveis e produzem impactos um sobre o outro. Para o autor, o que está em jogo na comunicação é "uma dinâmica do móvel e do imóvel" (Ibid.), um deslocamento, portanto: "comunicar é deslocar", escreve.

É notável como os diversos arranjos comunicativos, tanto de mobilidade simbólica quanto material, contribuem para produzir formas de sociabilidade e subjetividade nas cidades. Paul Virilio, arquiteto com formação militar, analisa insistentemente em sua obra a incidência que têm os meios de transporte e de comunicação a distância (sobretudo com o advento da transmissão em tempo real) sobre os espaços urbanos. Nessa relação, da ordem do confronto e mesmo do embate bélico, uma "energética da informação" imprime diretamente mutações à paisagem urbana, incidindo sobre "a resistência de seus materiais", a "persistência de sua existência" (VIRILIO, 1993: 67). Com os transportes, problemas análogos de investimento crescente na velocidade também desqualificariam o espaço físico e mesmo desterritorializariam arranjos anteriores de mobilidade, como teria se passado quando o transporte aéreo deslocou e desorganizou as viagens de trem (Ibid.: 72).

Se aceitamos, com Félix Guattari (1987, 1992; GUATTARI; ROLNIK, 1986), que a subjetividade pode ser concebida como produção - ou seja, processo (e não produto) constantemente engendrado no registro social a partir de fatores heterogêneos - e que o indivíduo é um "terminal", como nos arranjos das engrenagens dos computadores em rede, percebemos que todos esses fenômenos podem afetar diretamente a produção subjetiva nas cidades. Como mostrou Guattari (1992), para as cidades cada vez mais convergem os fluxos contemporâneos de ideias, mensagens, pessoas, objetos, de forma que a própria existência humana é engendrada ali. 
Assim, parece pertinente reunir num mesmo campo problemático todas estas questões. Também particularmente oportuno, pois nossa época nos tem imposto uma perversa economia mista dos fluxos comunicacionais. De um lado, uma violenta periferalização de amplos segmentos da população das cidades - com a perpetuação dos trajetos longos e difíceis para atingir os centros urbanos via meios de transporte cada vez mais precarizados (sedentarização forçada); com os trajetos ainda mais arriscados daqueles que são compelidos a deixar suas cidades arrasadas, por terra e mar, planetariamente, para um destino incerto (desterritorialização forçada). De outro, os meios de transmissão de informação a distância - sobretudo a partir do advento da tecnologia digital - imprimem, em contraste, uma crescente velocidade aos acontecimentos e práticas as mais diversas da vida cotidiana, se impondo, inclusive, no espaço aberto das cidades ao espocar em dispositivos móveis, como os celulares, e estender, assim, aos lugares públicos esse modo de vida. Ora deslocando, ora se aliando às mídias mais antigas, como o telefone e a televisão (esta última particularmente hábil em desenvolver adaptações técnicas e participar dos novos imperativos comunicacionais e subjetivos), essa energética informacional figura cada vez mais nos orçamentos das cidades, participa das organizações de vigilância e extração de dados dos indivíduos e, mais insidiosamente, vai produzindo atitudes e desejos.

Esses novos regimes contrastantes de velocidade atingem em cheio as cidades. Incidem, de fato, sobre seus espaços, geram novas situações comunicativas, inviabilizam outras, produzindo vida social e subjetiva. À parte um certo exagero, de que a própria tecnologia se encarrega para sua promoção, produzem efeitos bem concretos na vida nas cidades.

\section{Experimentação urbana}

A emergência das cidades está ligada ao povoamento espacial e à produção de espaços públicos. A ocupação coletiva gera heterogeneidade e a circulação redistribui a população nos diversos lugares, provocando, em alguma medida, uma dessegregação (CAIAFA, 2002, 2004a, 2007, 2013). Como indica Mumford (1961), a cidade se constitui a partir, sobretudo, de uma força de atração (magnet) para estrangeiros de toda sorte - imigrantes, comerciantes, visitantes, invasores. Embora o povoamento urbano envolva igualmente um processo de fixação, os fluxos urbanos não cessam de renovar a vida social nas cidades. Esse trânsito gera um espaço de exposição constante a descontinuidades.

As cidades surgem, portanto, instaurando um espaço de comunicação. Fernand Braudel (1979) mostra como, na Antiguidade, a solução imperial contrastava com a solução cidade. No primeiro caso, as cidades se concentravam em torno do palácio e só as capitais imperiais prosperavam. No segundo, que caracterizou o fenômeno urbano sobretudo na Europa, as cidades se desenvolviam em rede e num movimento de expansão mundial. Apesar de se distinguirem, falavam "uma linguagem fundamental", como o diálogo com o campo e a articulação com seus subúrbios e com outras cidades. Braudel (1979: 576) utiliza a expressão de Rudolf Häpke, "arquipélago de cidades" para indicar esse aspecto relacional e reticular. Assim também, Deleuze e Guattari denominam "vertical" o procedimento do Estado, opondo-o à expansão "horizontal" das cidades, que se constituem como "pontos-circuitos" e fazem um "contraponto sobre linhas horizontais". No poder que se produz no estabelecimento das cidades a integração é completa mas local, "de cidade em cidade" (DELEUZE; GUATTARI, 1980: 539).

Nesse espaço em constante movimento, gera-se um nomadismo tipicamente urbano, em que todos, inclusive os nativos, se tornam estrangeiros ao se exporem à variedade incessantemente renovada. Na cidade se produz um espaço de exterioridade, que devemos tomar bem radicalmente como um espaço feito de fora na medida em que a própria cidade se constitui como exterior (CAIAFA, 2007). 
É fato que a diversidade que caracteriza o meio urbano desde os seus inícios pode assumir diferentes destinos ao longo da história das cidades e nas diferentes configurações urbanas. A cidade medieval, como a descreve Sennett, opunha o espaço interior e ordenado das catedrais e das casas, onde a fé cristã podia prosperar, ao caos da rua, à urbs pagã de que era preciso se proteger (SENNETT, 1992). Mumford mostra como o regime de intimidação que reinava na Mesopotâmia acabou por obstar o movimento das trocas urbanas. Com as práticas de punição que culminaram no Código de Hamurabi e numa religião de deuses inclementes, esse regime acabou por transformar a cidade "numa espécie de prisão" - processo comparável, segundo o autor, aos estados totalitários da modernidade (MUMFORD, 1961: 89). Nas cidades modernas, a dependência do automóvel e a especulação capitalista do solo urbano trabalham contra a produção de espaços coletivos heterogêneos, lugar da comunicação urbana e vetor de transformação social e subjetiva. É possível, ainda, que simplesmente não nos deixemos afetar pela variedade urbana. Uma população em grande parte indiferente ao meio urbano diverso desenvolve, segundo Sennett, uma atitude de "desengajamento" (SENNETT, 1992: 129) que inviabiliza as trocas citadinas.

Em todos esses casos, a potência diferenciadora e dessegregadora presente nos inícios das cidades é neutralizada e a diversidade não produz, a rigor, diferença. A relação com os fluxos urbanos da diferença é uma experimentação, ou seja, algo que é preciso constantemente construir. Depende de ações de governança das cidades, assim como da produção de atitudes por parte dos próprios habitantes e visitantes enquanto ocupam e circulam pelos espaços urbanos. Essa experimentação é, em si, uma prática e constitui ela própria a sua garantia.

Quando há sucesso das forças diferenciadoras da cidade, os espaços públicos se tornam, de fato, espaços coletivos. Pode sobrevir, então, um aspecto notável dessa experimentação da diferença: a renovação e a invenção dos processos subjetivos e das modalidades de comunicação.

Os meios familiares e as pequenas aldeias, embora desenvolvam suas próprias experimentações, se caracterizam pela imposição de um alto grau de controle social. Em contraste, nas cidades imbuídas da potência da diferença, constrói-se um tipo particular de inserção ou de pertinência, distinto do grupo primário, em que nossa identidade não está tão marcada, gerando menos controle e, assim, um tipo de liberdade. Diferentemente de uma integração que nos acolhe mas nos encaixa em compartimentos reconhecíveis, ocupamos um lugar nos fluxos urbanos ao lado não de um conhecido ou um parente, mas de outros estranhos como nós. No âmbito dessa convivência e dessa pertinência fluida - se nos engajamos na novidade da experimentação -, há uma constante aprendizagem subjetiva na medida em que precisamos inventar formas de nos relacionar com esses outros e com o ambiente material diverso que ocupamos. Assim, nós próprios podemos nos transformar. Na comunicação urbana, igualmente, tendemos a não mobilizar os protocolos já conhecidos que utilizamos nos meios familiares. Pode resultar

${ }^{2}$ Para a questão do reconhecimento e da diferença nos processos comunicativos, cf. CAIAFA (2004b). um processo mais criador, uma comunicação não do reconhecimento, mas da diferença².

São situações que certamente trazem riscos - de resto, a solução familiar da pequena aldeia também, à sua maneira - e autores como Simmel (1964) e Wirth (1973) apostaram mais nesse aspecto, alertando para o sentimento de solidão e o estado de apatia que o excesso de estímulos numa grande cidade poderia provocar. Pode-se retorquir que a experimentação urbana, os efeitos criadores para a comunicação e a subjetividade são fatores de situação, ou seja, construídos no próprio exercício. Trata-se, nesses processos de enfrentamento marcados pelo imprevisível, de uma abertura e de um tipo especial de liberdade que podem se tornar possíveis. 


\section{As cidades e a história das mídias}

Como argumentei anteriormente, as condições de povoamento das cidades podem ser com proveito analisadas se consideramos, num mesmo campo problemático, os diferentes regimes de velocidade ou energéticas comunicacionais - arranjos de fluxos semióticos e também materiais - que se constroem e afetam seu espaço construído. Historicamente, formas de organização midiática incidem sobre as estratégias que inventamos para nos relacionar com os desconhecidos nas cidades e com os espaços que ocupamos. Ajudam a produzir, portanto, as condições para essa experimentação caracteristicamente urbana de reinvenção da vida social.

Consideremos uma indicação de Serge Daney, em sua obra Ciné journal, com o objetivo, agora, de examinar alguns aspectos dessa interferência e distinguir seus efeitos em diferentes configurações urbanas. Concisa, mas particularmente arguta, essa indicação nos fornece uma importante primeira pista.

Ciné journal reúne crônicas escritas por Daney entre 1981 e 1986, durante os anos de trabalho no jornal Libération. Conhecido crítico de cinema da revista Cahiers du Cinéma, Daney, naquele novo momento, se tornou também repórter. Prossegue com a crítica cinematográfica, mas escreve igualmente sobre televisão, esportes e festivais, e, ainda, o que nos interessa particularmente, viaja, visita locações de filmagem e está atento às cidades.

Assim, Daney (1998: 11) observa, numa visita a Moscou em março de 1983, que "descobrir uma capital" em viagem poderia nos dizer "a qual momento da história das mídias essa cidade pertence". Aponta, então, que Nova York é uma cidade "da época do cinema" e Tóquio, da televisão. Já Moscou, uma cidade ainda da pintura: "sua população (as filas de passantes que se alongam infinitamente sobre os paralelepípedos de pedra) não cessa de 'faire tableau'". E conclui: "é um mundo anterior às mídias" (ibid.).

Daney estava particularmente preocupado com o "confronto cinema-televisão", como indica Deleuze (1998) no prefácio ao livro Ciné journal. A emergência do televisual estaria ameaçando o cinema ao diluir sua imagem potente na profusão de imagens padronizadas. A câmera televisiva, numa "pobre gramática" (Daney, 1998: 148), tentava imitar o cinema com movimentos que resultavam em meros truques técnicos. Foi no contexto dessas preocupações que Daney, assistindo televisão num quarto de hotel em Moscou, fez estas observações sobre as cidades e a história das mídias.

A cada cidade, parece indicar Daney, podemos fazer corresponder um tipo de mídia. Moscou se apresenta como uma tela - os transeuntes estampados em constante movimento sobre os pisos de pedra, representados em diversas cenas com o ambiente urbano e compondo quadros que daí emergem e de novo mergulham sem cessar. Tóquio já ingressou no regime televisivo - talvez pela voragem de suas luzes, de seus anúncios coloridos, pela aceleração de trens e automóveis, de passarelas, viadutos e passantes, pelas cores que parecem espocar dos corpos e das coisas. Nova York é, todavia, uma cidade do cinema - habitável, infletida, talvez, de um movimento que evocaria a imagem cinematográfica como a concebe Daney, ou seja, imbuída de alteridade e resistente à uniformização pelo consumo.

Vamos nos deter no caso de Nova York. Nas vicissitudes do desenvolvimento da forma urbana nos Estados Unidos e da singularidade de Nova York nesse contexto, buscaremos outros elementos para prosseguir com a exploração da vizinhança entre as cidades e a história das mídias e das ressonâncias na produção de subjetividade e nas formas de comunicação. 


\section{Dispositivos alucinatórios}

No processo de urbanização dos Estados Unidos é possível distinguir dois momentos bem nitidamente. $O$ primeiro momento é de crescimento consistente das cidades americanas, que já no início do século XX era muito expressivo. É notável como esse crescimento urbano seguiu o ritmo sobretudo da expansão do transporte coletivo. Entre os anos 1860 e 1890, construíram-se, em algumas cidades, os elevated railways (els ou L's), elevados onde corriam bondes movidos a vapor inicialmente e depois a eletricidade. Era possível evitar o tumulto urbano viajando acima dele. Ônibus surgiram já na primeira década do século $X X$ e, nos primeiros anos do século, se inauguravam os grandes sistemas de metrô. $\mathrm{O}$ transporte underground tenderia, então, a predominar no país, definindo o perfil das cidades. A primeira linha do metrô de Boston foi aberta para operação comercial em 1897 e a de Nova York, em 1904. Uma terceira grande cidade da costa leste, Filadélfia, investiu igualmente num grande sistema de transporte underground ainda no primeiro quarto desse século (CUDAHY, 1990).

Num segundo momento, um processo que corria paralelo ao crescimento das cidades terminou por eclodir e determinar a ruptura com elas. Nesse contexto, uma reorganização da comunicação e do universo do transporte assumiu particular centralidade.

A partir dos anos 1920, teve início a construção de regiões residenciais nas periferias urbanas, os subúrbios, que foram crescendo em extensão e importância até a sua consolidação na década de 1950 . O incentivo à compra de casa própria nos novos lugares e a abertura de autoestradas por todo o território nacional, entre outros fatores, convergiram para produzir uma expressiva intervenção na forma urbana. As classes alta e média alta vão deixando as cidades e se estabelecendo nessas áreas, longe do transporte coletivo, do trânsito urbano e dos espaços públicos. Os shopping centers ao longo das autoestradas absorvem as atividades e os empregos. Os centros urbanos se esvaziam.

O transporte coletivo, que de início permitiu o êxodo, é igualmente destituído e o automóvel particular se torna a principal forma de conexão dos subúrbios com a cidade. Cessam os investimentos federais e a manutenção da infraestrutura existente se torna cada vez mais precária. O serviço é reduzido e mesmo desaparece em alguns lugares. $O$ espaço em torno das casas de família funciona como seus quintais, sendo raramente trilhados e a circulação se fazendo basicamente por automóvel particular.

Houve, por outro lado, a certa altura, um retorno, mesmo que modesto, dos investimentos, o que garantiu a recuperação relativa do transporte coletivo em alguns lugares. Mas a suburbanização já havia transformado o país e gerado um modo de vida. Essa configuração predomina até hoje, embora o grau de motorização no país oscile e tenha sofrido uma baixa entre 2006 e 2013 (SIVAK, 2018). Dados demonstram que novas gerações não valorizam tanto o automóvel, substituindo esse objeto tão emblemático do capitalismo pelo smartphone (MOSS, 2015), que, afinal, desempenha hoje um papel também central nos regimes capitalistas de subjetividade.

Embora esse modelo de ocupação urbana ou antiurbana seja uma criação britânica (DUPUY, 1998) e espaços residenciais suburbanos tenham se desenvolvido em torno de grandes cidades ocidentais em geral durante o século $\mathrm{XX}$, o processo radical de esvaziamento das cidades com alcance nacional e de produção de um modo de vida amplamente partilhado se deu, caracteristicamente, nos Estados Unidos.

Na Europa, a situação das cidades no pós-Guerra, quando predominava o esforço de reconstrução, e a posição menos central da indústria automobilística em geral 
no continente (com a notável exceção da Alemanha) contribuíram para que essa configuração não se generalizasse. Além disso, a própria antiguidade, a solidez histórica das cidades europeias as torna menos propensas a se adaptarem a essa configuração de cidade (BLACHE, 1955). No caso dos Estados Unidos, aspectos da própria história cultural do país, creio, favoreceram o êxodo das famílias americanas para essas áreas segregadas (CAIAFA, 1991).

No Brasil, o automóvel não encontrou cidades estabelecidas, como nos Estados Unidos e na Europa. O desenvolvimento urbano foi em grande medida contemporâneo da expansão do automóvel ou posterior. A dependência do automóvel também se desenvolveu nesse caso, mais ou menos pronunciada em cada cidade, mas sem a característica de modelo nacional dominante e fator poderoso de produção subjetiva. Vetor que atravessa o mundo capitalista, essa configuração de cidade encontrou solo particularmente fértil nos Estados Unidos.

Além do automóvel, há ainda que considerar o papel da televisão. Ela foi fator importante para a independência dos subúrbios da cidade central. O deslocamento até a cidade para uma sessão de cinema começou a se tornar dispensável, como observa Smerk (1991). De fato, a televisão surge historicamente no meio da sala de visitas como mídia familiar e de espectação sedentária. Virilio (1993: 10) observa que, quando abrimos a televisão e não somente a janela, ao dia solar e à iluminação elétrica acrescenta-se "um falso dia eletrônico". Essa produção fantasmática de exterioridade parece sobreviver nas adaptações mais recentes ao computador e a outros suportes, inclusive os portáteis, conduzidos ao espaço das ruas. Um exterior artificial pode tornar desnecessário sair à rua ou ocupá-la a partir dos referenciais ao longo do caminho.

Com a nítida distinção entre dois momentos - a prosperidade das cidades com o transporte coletivo e a construção de espaços públicos e, a certa altura, a suburbanização -, o desenvolvimento urbano nos Estados Unidos é especialmente eloquente em demonstrar os vínculos entre ocupação urbana e organização midiática. É possível distinguir cada fator que foi construindo o rompimento com a cidade.

Os espaços onde a densidade urbana desapareceu são tipicamente ocupados pela energética fantasmática de que participam, à sua maneira, o automóvel, a televisão e, mais recentemente, os diversos avatares do computador. Não é incomum que lojas, por exemplo, reservem a maior parte dos produtos às compras realizadas a distância e exibam prateleiras vazias aos clientes que ali comparecem. De início e por muitos anos, têm sido os catálogos impressos que possibilitam os pedidos feitos remotamente. Hoje, cada vez mais o e-commerce (comércio eletrônico via computador) esvazia quadras inteiras nas cidades ocidentais e fortemente nas norte-americanas, já que não é preciso mais sair para comprar ou comer, e as ruas se tornam, em consequência, menos frequentadas.

O correio atravessou o século XXe, no novo milênio, permanece sendo o meio de comunicação que conduz objetos planetariamente, inclusive por essas paisagens esvaziadas na experiência americana. Eficiente naquele país, leva seus pacotes às mais remotas paragens ao longo das autoestradas. Hoje, mundialmente, pouco se ocupa da entrega de cartas, posto que as mensagens são enviadas cada vez mais via o já quase antigo e-mail, Facebook, WhatsApp e outros repertórios digitais. Esses desdobramentos determinados pela comunicação digital, que criam algo novo ao mesmo tempo que estendem a ação das mídias fantasmáticas mais antigas, não são sem consequência para a ocupação das cidades, questão que apenas recentemente começa a ser explorada. $O$ telefone é igualmente um veículo que, nos Estados Unidos, desenvolveu muito cedo e com sucesso diversas facetas de comunicação a distância (secretárias eletrônicas, verificação remota de mensagens, conversas simultâneas etc.). 
São fluxos fantasmáticos os que mais circulam na cidade despovoada. Em trabalho anterior, chamei esses meios de comunicação a distância de dispositivos alucinatórios (CAIAFA, 1991) por promoverem magicamente a aparição dos ausentes - fantasmas ou alucinações.

Os smartphones, celulares com tecnologia "inteligente" que ampliam o alcance da comunicação por computador um dia iniciada sobre as escrivaninhas, vêm produzindo novos tipos de relação nos espaços urbanos (BERRY; HAMILTON, 2010; PICON, 2014). A tecnologia digital tem, de fato, se superposto cada vez mais aos espaços heterogêneos de confronto com estranhos nas cidades, fazendo valer a comunicação remota de forma imediata e particularmente eficaz em desterritorializar a comunicação face a face. É cada vez mais decisiva nessa tarefa, sobretudo se comparada com o já antigo telefone fixo e mesmo com a televisão, particularmente ativa em desenvolver facetas que a atualizam frente a esses novos meios sem precisar renunciar à sua inserção na sala da família. São verdadeiros "territórios informacionais" (LEMOS, 2010) que se impõem na cidade, recompondo à sua maneira os territórios urbanos.

Terão esses novos meios o poder de realizar uma erosão no terreno físico e social das cidades do mundo de dimensão tão expressiva quanto o automóvel realizou em companhia de outras mídias e cujo reino perdura até hoje?

A comunicação por computador tem sido mais frequentemente celebrada como veículo de democratização - por variadas razões, como por permitir uma comunicação descentralizada e ao alcance de muitos -, mas já se começou a explorar também como vem sendo eficiente em realizar um novo regime de dominação penetrante e molecularizado, assentado em grande parte na produção monumental de dados sobre os indivíduos por todo o planeta (BRUNO, 2009, 2010; CAIAFA, 2011; DUARTE; FIRMINO, 2010).

\section{Estratégias espaciais}

${ }^{3}$ A cidade de Nova York possui cinco boroughs (divisões municipais equivalentes aproximadamente a bairros): Manhattan (que apresenta mais características de metrópole, populosa, diversa e repleta de recursos urbanos), Brooklyn, Queens, The Bronx e Staten Island. Staten Island é o menos populoso e o que mais se aproxima da forma suburbana (áreas vazias, centralidade dos shoppings, motorização).

\footnotetext{
${ }^{4}$ Gentrification é a conversão de áreas de uma cidade para um regime de ocupação elitizada através da valorização programada do solo urbano.
}

Desde os primeiros estudos que realizei sobre a cidade dependente do automóvel nos Estados Unidos, tenho mostrado como Nova York, em muitos de seus lugares, constitui uma exceção a esse modelo (CAIAFA, 1991; BLACHE 1955). Não que os subúrbios não tenham crescido em torno quando todo o país começava a se organizar dessa maneira, mas o centro urbano não se tornou uma cidade fantasma, mesmo que tenha cedido a certa altura ao esvaziamento. Os subúrbios não se tornaram independentes da cidade e até hoje sua população utiliza as magníficas pontes que chegam a Manhattan para ajudar a povoar esse meio urbano diverso ${ }^{3}$. Um sistema integrado, diversificado e abrangente de transporte coletivo, além da preocupação histórica de várias administrações com o caráter público do espaço citadino - apesar da figura proeminente de Robert Moses, legendário defensor do automóvel e da segregação - contribuíram muito para essa sua resistência ao modelo nacional de cidade. Mesmo os efeitos da gentrificação ${ }^{4}$, fenômeno que vem atingindo com grande ímpeto as cidades do mundo em geral, não parecem até agora ter convergido de forma a transtornar ou inviabilizar a cidade como um todo. Nova York permanece, apesar de todas as perdas, uma cidade da densidade, do trânsito e da diversidade.

Daney, ao afirmar que Nova York é uma cidade do cinema alude, a meu ver, a estas suas características. O cinema chama à rua, convida a povoar as cidades. Em contraste com a televisão, a espectação cinematográfica se realiza em equipamentos coletivos e entre desconhecidos. Os cinemas de shopping, por seu turno, mesmo conservando algo do ambiente heterogêneo e coletivo, confinam a população diversa num ambiente fechado destinado ao consumo, convertendo o cinema ao regime familiar da televisão. É o cinema "de rua", ou "de calçada", que bem realiza esse aspecto coletivo da espectação cinematográfica. Estudos interessantes sobre salas de cinema demonstram este 
ponto (CLADEL et al., 2001; FERRAZ, 2009; SOUZA, 2010). O cinema tem sido um aliado do povoamento das cidades.

Observemos que a primeira baixa da cidade privatizada - conflagrada pela sedentarização forçada do transporte coletivo ausente ou precário, pela gentrificação, pelo predomínio do automóvel e pela neutralização dos encontros arriscados mas criadores com os estranhos no espaço urbano - é a alteridade.

No espaço seguro da casa ou do automóvel, assim como nos encontros em grande parte controlados nos meios digitais, somos poupados justamente da imprevisibilidade que nos leva a inventar e não a reconhecer. Mesmo que todas essas mídias possam criar outras inserções até referidas a algum local da cidade, antes de tudo nos arrebatam da fluência do movimento em rede em cujo regime de conexão e contágio as cidades, como vimos, investiram desde os seus inícios. A alteridade, se não obstada de uma vez por todas, é ao menos filtrada nesses dispositivos alucinatórios que, antigos ou recentes e seja por práticas mais primárias de inserção ou mais sutis de monitoramento, não atuam sem realizar em alguma medida o controle "ao ar livre" de que fala Deleuze (1990) ao descrever regime de dominação que vigora nas sociedades contemporâneas.

A comunicação é, assim, em grande parte colhida nas malhas dos protocolos que é preciso aprender e que se tornam um metro padrão dos contatos. Com o controle do espaço aberto de estrangeirismos, os processos subjetivos se reinscrevem no terreno do conhecido. A experiência de beira (SENNETT, 1992: 148) ou a distração de si mesmo (DELEUZE, 1974; TOURNIER, 1967) que outrem nos traz e que se acentua no espaço diverso das cidades (CAIAFA, 2007: 89-113, 2013: 47-72) perde muito de sua força. É a própria cidade, em suma, que corre o risco de se inviabilizar.

Nosso presente sempre nos oferece algo, mesmo se nos confronta com imperativos que é preciso perceber e questionar. Mas parece que não está garantido que as novas mídias - como já as antigas na figura do automóvel, por exemplo, e da televisão - venham sendo capazes, com a novidade que trouxeram, de repor a diferença, a alteridade que constitui a grande baixa na cidade esvaziada e controlada. Por outro lado, é certo que seria preciso, por cautela, evitar afirmações peremptórias diante de alguns fenômenos recentes ainda para serem explorados mais profundamente.

A cidade conflagrada pela energética digital é a configuração urbana emergente de maior destaque hoje no mundo capitalista e que se torna cada vez mais dominante. No âmbito desse fenômeno de ocorrência mundial que muito mais insidiosamente atinge as cidades periféricas, vulneráveis pela fraqueza de suas instituições e pela corrupção endêmica de seus governantes -, regiões inteiras das cidades são esvaziadas para abrir caminho para os negócios de empresas privadas. Urbanistas têm denominado esse tipo de iniciativa de "cidade-empreendimento" (ALVES, 2006; ARANTES, 2000; VAINER, 2000). Tipicamente, as cidades são geridas como se fossem empresas e esculpidas (em seu relevo material e social) com o objetivo de torná-las competitivas para atrair investidores e turistas. Busca-se implementar a digitalização generalizada dos recursos urbanos, desde salas de controle na administração até quiosques interativos para informação encaixada nos protocolos do entretenimento. $\mathrm{Na}$ cidade-negócio os lugares devem se prestar antes de tudo à alocação da produção de alta tecnologia. A cidade-empresa é, de fato, uma cidade tecnológica ou "cidade inteligente" (smartcity), repositório de dispositivos digitais.

Fenômeno que começa a se desenvolver a partir dos anos 1990, reúne experimentos emblemáticos como o planejamento empresarial de Baltimore, cidade americana, entre as décadas de 1970 e 1980, e a "revitalização" de Barcelona, na Espanha, que, embora a princípio preservasse alguma preocupação 
com o espaço público e a questão social, visou antes de tudo preparar sua candidatura para sediar os jogos olímpicos de 1992. O caso de Barcelona se tornou exemplo a ser seguido mundialmente pelos governos locais interessados em implementar esse modelo.

Arantes (2000) mostra como a ideia de que uma cidade pode ser gerida como um negócio está presente na tradição de longa data do urbanismo anglo-saxão que toma o solo urbano como alvo importante da especulação capitalista. Como afirma a autora, nos anos 1970 já se praticava nos Estados Unidos a concepção do urbanismo como instrumento de incremento de negócios. A configuração urbana que se consolida durante os anos 1950 nos Estados Unidos e que temos abordado aqui, faz parte dessa linha de filiação e já realizava uma forma de privatização dos espaços da cidade ao praticar a destituição dos pobres e o estímulo ao consumo nos imensos shoppings servindo as residências suburbanas.

Os projetos de cidade empresa que emergem a partir dos anos 1990 são em parte um desdobramento dessas primeiras ideias, embora tragam certamente novidades. É curioso, a propósito, que a construção de infraestruturas urbanas de transporte coletivo figure e até se destaque nesses projetos. Mas, se atentarmos para casos concretos, vemos de que forma o "coletivo" entra no receituário. 0 bonde ou tram (ou VLT, veículo leve sobre trilhos) implementado em 2016 no centro do Rio de Janeiro tem se prestado muito pouco ao uso pela população local ou por visitantes que não se inscrevem no consumo turístico. A sua construção perfurou quilômetros de chão, remodelou toda a área, inverteu as mãos das ruas e exigiu a reorganização e mesmo a extinção de linhas de ônibus. A questão não é, de fato, o transporte, mas o turismo e a alocação de tecnologia. Lembremos que o VLT carioca foi construído no contexto de uma intervenção de vulto na cidade visando prepará-la, justamente, para sediar as Olimpíadas de 2016, ocasião em que o Porto do Rio de Janeiro foi, igualmente, basicamente destruído e reconstruído seguindo a mesma receita.

A cidade-empresa atualiza, assim, de forma bem nítida a relação entre organização midiática e ocupação urbana que temos discutido aqui.

Não nos deve escapar, por outro lado, que em muitas das cidades que têm sido alvo de intervenções desse tipo outros processos podem desviar, ainda que pontualmente, o curso dos eventos que se pretendia imperativo e inexorável.

No Rio de Janeiro, mesmo no centro convulsionado e no porto remodelado para abrigar edificações monumentais para escritórios de empresas e museus "high tech", a ocupação coletiva vem contornando esses obstáculos. Seja, por exemplo, com as caminhadas a pé que não se tornaram obsoletas - mesmo que hoje dificultadas pelo tumulto do trânsito caótico no centro da cidade ou pelas intervenções que, no Porto, converteram o caminhar a meros giros ao redor dos prédios vistosos -, seja com os shows e blocos populares, com a reunião em bares e no que restou das ruas ou com outras situações de encontros citadinos a baixo preço e fora dos parâmetros estipulados para o turismo.

São estratégias espaciais que permitem a experimentação urbana contra o trânsito nos dispositivos fantasmáticos ou no falso transporte da diversão turística.

Evoquemos, novamente e para terminar, Nova York, cidade do cinema segundo Daney. Grande exceção, como vimos, à desertificação das cidades americanas, até hoje e a despeito da gentrificação que tem convertido algumas de suas regiões ao regime do negócio, em Nova York também encontramos o contágio de ideias estranhas, a circulação de estrangeiros e os encontros imprevisíveis.

A experimentação urbana da diferença, que nos leva a inventar novas formas de comunicação e que renova o ar nas subjetividades em constante produção no 
registro coletivo, insiste em vários momentos e cidades por estratégias espaciais que aprendemos a desenvolver. Arriscada, não é uma conquista de uma vez por todas, mas algo em que podemos, por enquanto, continuar apostando e que tem no próprio exercício a sua garantia.

\section{Referências}

ALVES, G. da A. O modelo de Barcelona: uma análise crítica. GEOUSP: Espaço e Tempo, São Paulo, n. 20, p. 185-186, 2006. Disponível em: http://bit.ly/2JzkgrD. Acesso em: 31 ago. 2018.

ARANTES, O. B. F. Uma estratégia fatal: a cultura nas novas gestões urbanas. In: ARANTES, O. B. F.; VAINER, C.; MARICATO, E. (org.). A cidade do pensamento único: desmanchando consensos. Petrópolis: Vozes, 2000. p. 11-74.

BERRY, M.; HAMILTON, M. Changing urban spaces: mobile phone on trains. Mobilities, [S. I.], v. 5, n. 1, p. 111-129, fev. 2010. Disponível em: http://bit.ly/2VKTnlT. Acesso em: 31 ago. 2018.

BLACHE, J. Coup d'oeil sur les villes américaines. Revue de Géographie de Lyon, Géocarrefour, Lyon, v. 30, p. 1-18, 1955. Disponível em: http://bit.ly/30BswfX. Acesso em: 31 ago. 2018.

BRAUDEL, F. Civilisation matérielle, économie et capitalisme, XVe-XVIIle siècle. Paris: Armand Colin, 1979.

BRUNO, F. Vídeo-vigilância e mobilidade no Brasil. In: LEMOS, A.; JOSGRILBERG, F. (org.). Comunicação e mobilidade: aspectos socioculturais das tecnologias móveis de comunicação no Brasil. Salvador: Edufba, 2009. p. 137-150.

BRUNO, F. Mapas de crime: vigilância distribuída e participação na cultura contemporânea. In: BRUNO, F.; KANASHIRO, M.; FIRMINO, R. (org.). Vigilância e visibilidade: espaço, tecnologia e identificação. Porto Alegre: Sulina, 2010. p. 155-173.

CAIAFA, J. Fast trips and foreignnesses: an anthropological study of hispanic women as other in American Society. 1991. Tese (Doutorado em Antropologia) Cornell University, Ithaca, 1991.

CAIAFA, J. Jornadas urbanas: exclusão, trabalho e subjetividade nas viagens de ônibus na cidade do Rio de Janeiro. Rio de Janeiro: Editora FGV, 2002.

CAIAFA, J. Une aventure propre aux villes. Chimères, Paris, n. 54-55, 2004a.

CAIAFA, J. Comunicação da diferença. Revista Fronteiras: Estudos Midiáticos, São Leopoldo, v. 6, n. 2, p. 47-56, jul./dez. 2004b. Disponível em: http://bit.ly/2HR9KZA. Acesso em: 31 ago. 2018.

CAIAFA, J. Aventura das cidades: ensaios e etnografias. Rio de Janeiro: Editora FGV, 2007.

CAIAFA, J. Aspectos do múltiplo nas sociedades da comunicação. Revista Contracampo, Niterói, n. 22, p. 130-146, fev. 2011. Disponível em: http://bit.ly/2Erp8L2. Acesso em: 31 ago. 2018.

CAIAFA, J. Trilhos da cidade: viajar no metrô do Rio de Janeiro. Rio de Janeiro: 7 Letras, 2013. 
CAREY, J. W. Communication as culture: essays on media and society. Boston: Unwin Hyman, 1989.

CLADEL, G.; FEIGELSON, K.; GÉVAUDAN, J.-M.; LANDAIS, C.; SAUVAGET, D. (org.). Le cinéma dans la cité. Paris: Éditions du Félin, 2001.

COOLEY, C. H. The significance of communication. In: COOLEY, C. H. Social organization: a study of the larger mind. New York: Charles Scribner's Sons, 1909. p. 61-65. Disponível em: http://bit.ly/2JVAivf. Acesso em: 31 ago. 2018.

CUDAHY, B. J. Cash, tokens, and transfers: a history of urban mass transit in North America. New York: Fordham University Press, 1990.

DANEY, S. Ciné journal: volume II, 1983-1986. Paris: Cahiers du Cinéma, 1998.

DELEUZE, G. Michel Tournier e o mundo sem outrem. In: DELEUZE, G. Lógica do sentido. São Paulo: Perspectiva, 1974. p. 311-330.

DELEUZE, G. Lettre à Serge Daney: optimisme, pessimisme et voyage. In: DANEY, S. Ciné journal: volume I, 1981-1983. Paris: Cahiers du Cinéma, 1998. p. 97-112.

DELEUZE, G. Post-scriptum sur les sociétés de contrôle. In: DELEUZE, G. Pourparlers (1972-1990). Paris: Les Éditions de Minuit, 1990. p. 240-252.

DELEUZE, G.; GUATTARI, F. Mille plateaux: capitalisme et schizophrénie. Paris: Les Éditions de Minuit, 1980.

DUPUY, G. O automóvel e a cidade. Lisboa: Instituto Piaget, 1998.

DUARTE, F.; FIRMINO, R. Espaço, visibilidade e tecnologias: (re)caracterizando a experiência urbana. In: BRUNO, F.; KANASHIRO, M.; FIRMINO, R. (org.), Vigilância e visibilidade: espaço, tecnologia e identificação. Porto Alegre: Sulina, 2010. p. 94-113.

FERRAZ, T. G. A segunda cinelândia carioca: cinemas, sociabilidade e memória na Tijuca. Rio de Janeiro: Multifoco, 2009.

GUATTARI, F. Revolução molecular: pulsações políticas do desejo. São Paulo: Brasiliense, 1987.

GUATTARI, F. Caosmose: um novo paradigma estético. Rio de Janeiro: Editora 34, 1992.

GUATTARI, F.; ROLNIK, S. Micropolítica: cartografias do desejo. Petrópolis: Vozes, 1986.

HAYE, Y. de la. Marx \& Engels on the means of communication: the movement of commodities, people, information \& capital. New York: International General; Bagnolet: International Mass Media Research Center, 1980.

LEMOS, A. Cultura da mobilidade. Revista FAMECOS, Porto Alegre, n. 40, p. 28-35, dez. 2009. Disponível em: http://bit.ly/30BR8Fb. Acesso em: 31 ago. 2018.

LEMOS, A. Mídias locativas e vigilância: sujeito inseguro, bolhas digitais, paredes virtuais e territórios informacionais. In: BRUNO, F.; KANASHIRO, M.; FIRMINO, R. (org.). Vigilância e visibilidade: espaço, tecnologia e identificação. Porto Alegre: Sulina, 2010. p. 61-93.

MATTELARD, A. La mondialisation de la communication. Paris: PUF, 1996.

MORLEY, D. Communications and transport: the mobility of information, people and commodities. Media, Culture \& Society, [S. I.] v. 33, n. 5, p.743-759, 2011. 
MOSS, S. End of the car age: how cities are outgrowing the automobile. The Guardian, London, 28 abr. 2015. Disponível em: http://bit.ly/2WeheyU. Acesso em: 31 ago. 2018.

MUMFORD, L. The city in history. New York: Harcourt, Brace \& World, 1961.

PACKER, J.; OSWALD, K. From windscreen to widescreen: screening technologies and mobile communication. The Communication Review, [S. I.], v. 13, n. 4, 2010.

PICON, A. La ville des réseaux: un imaginaire politique. Paris: Manucius, 2014.

SENNETT, R. The conscience of the eye. New York: W. W. Norton \& Company, 1992.

SIMMEL, G. The metropolis and mental life. In: WOLFF, K. H. (org.). The sociology of Georg Simmel. New York: Free Press, 1964. p. 409-424.

SIVAK, M. Has motorization in the U.S. peaked? Part 10: vehicle ownership and distance driven, 1984 to 2016. Ann Arbor: The University of Michigan, 2018. Disponível em: http://bit.ly/2EtEorO. Acesso em: 31 ago. 2018.

SMERK, G. M. The federal role in urban mass transportation. Bloomington: Indiana University Press, 1991.

SOUZA, M. C. S. Nas ruas do cinema: por uma cartografia dos vestígios cinematográficos no espaço urbano do Rio de Janeiro. Revista Extraprensa, São Paulo, v. 3, n. 3, p. 823-833, 2010. Disponível em: http://bit.ly/2YJWFI9. Acesso em: 31 ago. 2018.

TOURNIER, M. Vendredi ou les limbes du Pacifique. Paris: Gallimard, 1967.

VAINER, C. B. Pátria, empresa e mercadoria: notas sobre a estratégia discursiva do Planejamento Estratégico Urbano. In: ARANTES, O. B. F.; VAINER, C.; MARICATO, E. (org.). A cidade do pensamento único: desmanchando consensos. Petrópolis: Vozes, 2000. p. 75-103.

VIRILIO, P. O espaço crítico. Rio de Janeiro: Editora 34, 1993.

WIRTH, L. O urbanismo como modo de vida. In: VELHO, O. G. (org.). O fenômeno urbano. Rio de Janeiro: Zahar, 1973. p. 90-113. 